\title{
Fashion Renting: An Exploratory Study of User and Non-User Behaviors
}

Heeju Noe and Jonghan Hyun, Kent State University, USA

Keywords: Fashion renting, focus group, consumption value theory

Fashion renting (FR), a form of collaborative consumption that allows consumers to focus on using rather than owning products (Park \& Armstrong, 2017), is a business model that is recently gaining the attention of fashion practitioners. According to industry reports, the global online FR market is expected to reach the economic value of 2 billion dollars by 2025 (e.g., MarketWatch, 2019). Given the above, it is not surprising that the academia has also been paying considerable attention to examining consumers that engage in FR and collaborative fashion consumption in general (e.g., Becker-Leifhold \& Iran, 2018; Park \& Armstrong, 2019). As a result, the current fashion discipline possesses a substantial understanding of the important factors that encourage consumers to use FR services. One concern, however, is that relatively little attention has been placed on consumers who do not use FR services. This is an important gap in research especially considering the fact that understanding non-users of products or services often lead to valuable and distinct implications. For instance, Li and Huang (2016) suggested strategies to improve teachers' adoption of game-based learning by investigating how non-adopters differ from adopters in terms of their personal characteristics. Similarly, Finch (2006) examined the buyers and non-buyers of organic food and identified the familiarity with organic food as a unique factor that only impacts the behavior of non-buyers. Accordingly, in this study, we propose that different sets of factors trigger the decision to use or not use FR services, and that the simultaneous investigation of both aspects will provide meaningful results for fashion researchers as well as practitioners.

\section{Method}

In order to test our proposal, two separate focus group interviews, for users and non-users of FR services, were conducted. We recruited a total of 13 participants who identified themselves as either users or non-users of FR services. The two focus group interviews were held separately for 40 minutes under the guidance of a researcher who presented relevant questions for discussion. Questions presented by the researcher were developed based on the focus group interview technique suggested by the Consumption Value Theory (Sheth et al., 1991). This technique was considered especially appropriate due to its usefulness in uncovering why consumers choose to approach or avoid certain products or services (for example, see Finch, 2006). Specifically, the questions were structured around the five consumption values (function, emotional, social, epistemic, and conditional) to investigate how different factors are considered when making the decision to use or not use FR services. These interviews were recorded and transcribed verbatim for further analysis. Our results are presented below along with the interview questions presented for each consumption value.

\section{Results \\ Functional: What are the benefits or problems associated with FR services?}


Benefits that encourage users to approach FR services (saving money, convenience, and access to trendy products) were in line with previous findings (Park \& Armstrong, 2019; Tao \& $\mathrm{Xu}, 2018$ ). Problems that cause non-users to avoid FR services (additional fees, lack of ownership) were also consistent with previous studies in general (Becker-Leifhold \& Iran, 2018; Lang et al., 2019). However, a distinct finding was that hygiene was not a major discouraging factor, unlike what has been proposed in the literature (e.g., Lang et al., 2019): "Gen Z and Millennials have less squeamishness about buying or renting things that other people have worn". Also interesting to note is that non-user participants seemed to trust FR companies' ability to maintain clean products as shown by the following excerpt: "bugs or something like dirt would ruin (the products) really bad, so I feel like they (FR companies) would make an effort not to let that happen".

Social: What groups of people do you believe are most and least likely to use FR services?

Participants indicated that users of FR services are likely to be women, fashion-forward, actively working, aged 20 to 40, and adventurous, whereas non-users are likely to be men, women aged 50 or over, and unfashionable. Some example excerpts from the non-user interview include: "(older people) would be like, no, just buy it"; "(older people) would think it is a waste of money".

Emotional: How do you feel about using or not using FR services?

Feelings mentioned by the users of FR services (happy, satisfied, exciting, and positive emotions) were consistent with the hedonic motives that Becker-Leifhold and Iran (2018) identified. Non-users, on the other hand, mentioned that they felt negative emotions due to their inability to explore or try new styles ("I do kind of feel jealous...they are exploring new styles", "I feel negative [about FR services] because I want to use them [but I can't]").

Epistemic: What triggered your decision to approach or avoid FR services?

User participants mentioned new experience as the major reason for approaching FR services, whereas non-users mentioned price and complexity of renting procedure as the foremost barriers.

Conditional: Are there any circumstances or situations that would cause you to start or stop using FR services?

Poor customer service, price hikes, and changes in finances were discussed as conditional factors that would cause user participants to stop using FR services. Non-user participants, on the other hand, mentioned that they would consider using FR services in case of formal events, job interviews, or when going on vacations.

\section{Discussion}

In all, our analysis supports our initial assumption that different sets of factors trigger the decision to use or not use FR services. Specifically, while saving money was one of the motivations for users, non-users hardly perceived the same benefit. This finding suggests the need to alter non-users' perception toward the price barrier via appropriate marketing strategies. Furthermore, non-users' responses to the conditional value question implies the importance of target-specific marketing for customers that are expected to be under certain circumstances (e.g.,

Page 2 of 3

(c) 2020 The author(s). Published under a Creative Commons Attribution License (https://creativecommons.org/licenses/by/4.0/), which permits unrestricted use, distribution, and reproduction in any medium, provided the original work is properly cited.

ITAA Proceedings, \#77 - https://itaaonline.org 
consumers preparing for job interviews). Future studies may utilize our results as a starting point for creating measurement scales that can identify users and non-users of FR services.

\section{References}

Finch, J. E. (2005). The impact of personal consumption values and beliefs on organic food purchase behavior. Journal of Food Products Marketing, 11(4), 63-76.

Kang, J., Kim, S.-H., (2013). What are consumers afraid of? Understanding perceived risk toward the consumption of environmentally sustainable apparel. Family and Consumer Sciences Research Journal. 41(3), 267-283.

Lang, C., Seo, S., \& Liu, C. (2019). Motivations and obstacles for fashion renting: a crosscultural comparison. Journal of Fashion Marketing and Management: An International Journal, 23(4), 519-536.

Li, S. C. S., \& Huang, W. C. (2016). Lifestyles, innovation attributes, and teachers' adoption of game-based learning: Comparing non-adopters with early adopters, adopters and likely adopters in Taiwan. Computers and Education, 96, 29-41.

MarketWatch (2019). Online clothing rental market is expected to display higher growth rate due to changing fashion trends and rising penetration of Internet. Retrieved from https://www.marketwatch.com/press-release/online-clothing-rental-market-is-expectedtodisplay-higher-growth-rate-due-to-changing-fashion-trends-and-rising-penetrationofinternet- radiant-insights-inc-2019-05-27

Park, H., \& Armstrong, C. M. J. (2017). Collaborative apparel consumption in the digital sharing economy: An agenda for academic inquiry. International Journal of Consumer Studies, 41(5), 465-474.

Park, H., \& Joyner Armstrong, C. M. (2019). Is money the biggest driver? Uncovering motives for engaging in online collaborative consumption retail models for apparel. Journal of Retailing and Consumer Services, 51, 42-50.

Sheth, J., Newman, B., and Gross, B. (1991). Consumption Values and Market Choices. Cincinnati, OH: South-Western Publishing.

Tao, Q., \& Xu, Y. (2018). Fashion subscription retailing: an exploratory study of consumer perceptions. Journal of Fashion Marketing and Management, 22(4), 494-508.

Page 3 of 3

(c) 2020 The author(s). Published under a Creative Commons Attribution License (https://creativecommons.org/licenses/by/4.0/), which permits unrestricted use, distribution, and reproduction in any medium, provided the original work is properly cited.

ITAA Proceedings, \#77 - https: //itaaonline.org 